\title{
Corneal Decompensation
}

National Cancer Institute

\section{Source}

National Cancer Institute. Corneal Decompensation. NCI Thesaurus. Code C50507.

Endothelial decompensation that is manifested by opacity of the cornea. The condition

often occurs as a nonspecific response to mechanical injury from incidental corneal contact by intraocular instruments during surgery; chemical injury from the improper use of intraocular drugs, drugs containing preservatives, or from residues from inadequate rinsing of detergents or other residues from surgical instruments. The most common causes of corneal endothelial decompensation in the adult population are cataract removal/IOL-related endothelial loss and Fuchs dystrophy. When severe, corneal endothelial decompensation requires corneal transplantation. 